\title{
CLIMA E PLANEJAMENTO AMBIENTAL URBANO: ESTUDO PRELIMINAR PARA MONTES CLAROS-MG
}

\author{
CLIMATE AND URBAN ENVIRONMENTAL PLANNING: A PRELIMINARY STUDY FOR MONTES \\ CLAROS - MG
}

\author{
Gomes, Patrícia Silva \\ Mestranda em arquitetura e urbanismo na UFSC-CTC. \\ E-mail: sgomespatricia@yahoo.com.br
}

\section{RESUMO}

O presente trabalho procura analisar o comportamento climático da cidade de Montes Claros, localizada na região norte de Minas Gerais, que apresenta um clima quente e seco, de modo a identificar a formação de ilhas de calor, ilhas de frescor e possíveis áreas com desconforto térmico. Os dados obtidos com a análise do comportamento termodinâmico serão utilizados para a proposição de sugestões que possam auxiliar aos órgãos municipais no planejamento ambiental e urbano do município.

Palavras-chave: Clima urbano, planejamento ambiental, planejamento urbano.

\begin{abstract}
The present work intends to analyze the climatic behavior of the Montes Claros city, located in the region north of Minas Gerais, that it presents a hot and dry climate, in order to identify the formation of heat islands effect, coolness islands effect and possible areas with thermal discomfort. The data gotten with the analysis of the thermodynamic behavior will be used for the proposal of municipal suggestions that can assist the agency in the ambient and urban planning of the city.
\end{abstract}

Key words: Urban climate, ambient planning e urban planning.

\section{1 - Introdução}

O Brasil, desde a metade do século XX, apresentou uma rápida urbanização. Esse processo, caracterizado especialmente pela formação de metrópoles, deu-se de forma intensa e descontrolada resultando em modificações na natureza.

Em virtude dessas constatações, pode-se perceber que o ambiente urbano dessas cidades foi alterado pelos elevados índices de adensamento e impermeabilização do solo, retificação e canalização dos cursos d'água e crescente substituição de áreas verdes por áreas construídas. A situação se agrava na medida em que o uso do solo torna-se especulativo. Como resultado tem-se a criação de uma natureza humanizada e artificial.

Lefebre (1969), ao se referir à destruição do ambiente natural nas cidades e sua reconstrução diz que o novo ambiente urbano gerado é de uma natureza segunda, constituída pela cidade e o urbano'.

Dessa forma, uma série de fenômenos tais como ilhas de calor, polvição do ar, chuvas intensas, inundações, desabamentos passam a fazer parte do cotidiano urbano.

O processo de urbanização é bastante significativo em termos de modificações do clima em escala local, gerando um clima próprio. Pois, o clima urbano é entendido como um sistema que abrange um fato natural (clima local) e um fato social (a cidade) (MONTEIRO; MENDONÇA, 2003)².

Diversos fatores contribuem para a modificação do clima local, Lowry (1967), enumera alguns deles: os materiais utilizados nas construções e na pavimentação, o sítio natural, as atividades 
humanas geradoras de calor, a remoção das águas superficiais e a presença de polventes no $a r^{3}$.Em relação ao espaço construído urbano, pode-se afirmar que a boa condutibilidade térmica dos materiais, bem como, a rugosidade das superfícies, contribuem para a redução da evaporação e o aquecimento, devido ao armazenamento de calor.

O ritmo e a magnitude de produção e armazenamento de calor nas cidades são profundamente alterados e diferenciados em relação à zona rural. Dessa constatação é que decorre o conceito de ilha de calor urbana, que foi definido por oke. (1981) como uma tendência observada de ocorrer na cidade temperaturas mais elevadas que no seu entorno rural imediato ${ }^{4}$.

As alterações climáticas na atmosfera urbana geram o stress humano, além de ocasionarem o maior consumo de energia e pode comprometer o desequilíbrio térmico em uma escala maior.

Segundo alguns autores, apesar de ser polêmica a idéia da influência da urbanização na mudança climática global, acredita-se que os climas urbanos podem representar um microcosmo dos climas de larga escala do futuro, tendo em vista o processo de aquecimento global. E os pesquisadores geralmente concordam sobre o impacto do ambiente construído no clima, pelo menos em nível local ou mesoclimático ${ }^{5}$.

A presença de vegetação e demais recursos ambientais em áreas urbanas são imprescindíveis para a qualidade de vida. Desde a cidade industrial até a cidade pós-moderna que os recursos naturais, em especial as áreas verdes, são utilizados como fatores físicos e psicológicos da manutenção do bem-estar social.

A cobertura vegetal foi retirada muito rapidamente da paisagem natural e rural na zona tropical, o que resultou em alterações no equilíbrio de energia, já que a vegetação além de absorver a radiação solar excessiva, atua através da evapotranspiração, no resfriamento e umidificação do ar, contribuindo, em ambas as vias, para o equilíbrio térmico.

Diante desse quadro, é possível afirmar que os problemas ambientais, fruto da urbanização das metrópoles brasileiras, atingiram dimensões alarmantes, e por vezes, irreparáveis, devido à urbanização já consolidada. Com isso, o planejamento da expansão urbana, o controle dos parâmetros de verticalização e uso do solo, bem como o planejamento ambiental, tornam-se essenciais para preservar as áreas ambientais ainda presentes no tecido urbano e para melhorar a qualidade de vida dos habitantes.

Em outra via, porém, as cidades de médio porte passaram a apresentar, a partir dos anos 1980, como constatado pelo Censo do IBGE, um crescimento urbano muito intenso, superior inclusive ao das cidades de maior porte (taxas de crescimento urbano de 4,8\% e 1,3\% respectivamente) 6 .

Em virtude dessa constatação, as cidades de médio porte demográfico, como é o caso de Montes Claros-MG, objeto de estudo do presente trabalho, merecem especial atenção em estudos de climatologia urbana, já que os dados obtidos poderiam auxiliar no planejamento ambiental e urbano, pois, o processo de urbanização nesses locais ainda está acontecendo, diferentes das grandes cidades, que apresentam urbanização praticamente consolidada.

O clima urbano, conforme metodologia adotada por Monteiro (1976), pode ser entendido como um sistema singular, aberto, evolutivo, dinâmico, adaptativo e passível de auto-regulação, denominado como Sistema Clima Urbano (SCU). Esse sistema classifica-se em três subsistemas: o termodinâmico, que investiga a formação de ilhas de calor, ilhas de frescor e demais formas de desconforto térmico; o físico-químico que estuda a polvição do ar; e o hidrometeórico, que analisa as alterações pluviais tais como as inundações ${ }^{7}$.

Os estudos de climatologia urbana, de modo especial em regiões tropicais como o Brasil, tornam-se essenciais na compreensão dos problemas ambientais resultantes da urbanização. Além disso, os resultados obtidos podem auxiliar no planejamento ambiental e urbano ao englobar 
soluções que contemplem índices adequados de uso e ocupação do solo e a preservação ou reconstituição de áreas verdes e demais recursos naturais.

Mendonça (2003) ressalta que as cidades de pequeno e médio porte de zonas tropicais como - Brasil, só muito recentemente tiveram seus ambientes climáticos como objeto de estudo. Nestas localidades, a variação sazonal da precipitação e da umidade do ar é consideravelmente importante na determinação da atmosfera urbana, e seu estudo pode auxiliar na compreensão dos vários problemas urbanos das cidades tropicais ${ }^{8}$.

A partir dos anos 1990, no Brasil, percebe-se que a questão ambiental começou a tomar posição de destaque. Nesse viés, Duarte (2003) constata que a variável ambiental foi incluída no planejamento urbano como um dos eixos principais de orientação das novas leis urbanísticas de uso e ocupação do solo, resultado do estado de agravamento dos níveis de degradação ambiental das cidades, decorrente de um processo de urbanização acelerado?.

Há um consenso sobre o grande potencial da utilização dos estudos de climatologia ao planejamento de cidades, já que as informações climáticas podem resultar na construção de ambientes mais agradáveis.

Segundo Duarte (2003), já foram quantificados, através de alguns estudos, a correlação entre temperatura do ar e alguns parâmetros de uso do solo que podem ser regulamentados. Além disso, a autora expõe que alguns trabalhos na área já demonstram claras diferenças de desempenho térmico entre superfícies naturais e construídas.

Em relação ao planejamento ambiental, alguns estudos, inclusive brasileiros, vêm buscando quantificar a importância dos recursos naturais, tais como massas de vegetação e de água, para o balanço de energia e a adequação climática.

Tudo isso, vem confirmar a importância da aplicação dos conhecimentos do fenômeno climático na orientação do planejamento ambiental urbano. Especialmente em países tropicais como - Brasil, no qual, tem sido comum o acontecimento de episódios climáticos severos, advindos da sobreposição dos vários fatores climáticos relacionados com o clima urbano.

É necessário constar também que o bem-estar percebido no espaço público urbano muito tem a ver com conforto térmico do local.

Keoble et. al (1990) apud Duarte (2003), estudando a legislação de diversos países europeus, encontraram muitos instrumentos comuns que demonstram que o planejamento está cada vez mais associado à qualidade de vida, à ecologia, ao controle de polvição e à eficiência energética.

Contudo, o desafio é transformar os dados de clima urbano em critérios de ocupação, em índices urbanísticos, em dados para projetos dos espaços externos dos edifícios a fim de amenizar o rigor climático nas zonas tropicais como o Brasil. Oferecendo dessa forma, a oportunidade para que o conhecimento que vem sendo acumulado sobre o meio ambiente possa ser incorporado às legislações municipais.

A partir dessa reflexão, e levando se em consideração que a climatologia influencia nas questões ambientais e urbanas, surge o seguinte questionamento que norteia esse trabalho: como orientar/conduzir o planejamento urbano e ambiental para que se possa atingir um melhor nível de qualidade no espaço das cidades?

Nessa perspectiva, pretende-se com esse trabalho fazer uma análise climática da cidade de Montes Claros-MG, no que tange ao comportamento termodinâmico descrito no SCU, de modo a fornecer informações que venham a ser utilizadas no planejamento da paisagem e no planejamento urbanístico do município. 


\section{2 - Caracterização da área de estudo}

A cidade de Montes Claros está localizada no norte do estado de Minas Gerais, entre os paralelos $16^{\circ} 43^{\prime} 41^{\prime \prime}$ e longitude $43^{\circ} 51^{\prime} 54^{\prime \prime}$, a uma altitude de 638 metros. O clima da cidade é quente e seco, com temperaturas médias anuais de $24,2^{\circ} \mathrm{C}$. O relevo é relativamente plano com a ocorrência de algumas serras.

O município apresenta uma população de 336.132 habitantes $^{10}$ e possui um crescimento populacional bastante acelerado, devido à sua abrangência regional: maior pólo econômico e de serviços de toda a região norte de Minas e vale do Jequitinhonha, ambas pertencentes à área mineira da Sudene, já que as características geográficas e sociais se assemelham ao Nordeste brasileiro. O município exerce influência ainda no sul do estado da Bahia atraindo populações advindas desse local.

Devido aos incentivos da Sudene algumas indústrias se instalaram no município, o que ocasionou a implantação de um distrito industrial na parte norte-noreste. Esse fato fortaleceu a abrangência regional do município.

Em relação às questões urbanas, a cidade tem-se expandido rapidamente, sobretudo nas regiões periféricas. A região central é marcada por uma elevada impermeabilização do solo e um incipiente processo de verticalização. A vegetação urbana na região central limita-se a algumas praças e vias arborizadas. Grande parte dos cursos d'água do município foram canalizados, retificados e tiveram a vegetação ciliar removida com a implantação de avenidas sanitárias.

Outra constatação importante, é que as áreas verdes do município estão inseridas quase que exclusivamente na região sudoeste, onde localizam-se os parques: Guimarães Rosa que é um parque linear constituído pelas matas ciliares do córrego Vieiras, o Milton Prates (com lago artificial) e o Sapucaia o maior em extensão. Nessa região estão implantados os bairros mais nobres que apresentam, em sua maioria, habitações unifamiliares.

Como mecanismo de adequação microclimática, foi proposto, há alguns anos, a construção de algumas lagoas artificiais em distintos pontos da cidade. Porém, apenas uma foi construída na região nordeste, sendo que o local previsto para a implantação das demais, em terrenos de fundos de vale, já foram urbanizados.

Como o clima da cidade é quente e seco e as temperaturas elevadas durante quase todo o ano, as sensações de desconforto térmico e a formação de gradientes horizontais de variação de temperatura, ou seja, temperaturas no centro mais elevadas que na periferia, tornamse evidentes.

Em relação ao regime pluvial, o município localiza-se no Polígono das Secas, apresentando chuvas intensas no período de verão e precipitações escassas no decorrer do ano.

Diante dessa descrição, percebe-se que um estudo climático da cidade de Montes Claros torna-se necessário, pois, as informações técnicas, com base científica, poderão auxiliar no planejamento ambiental e urbano, através de planos de reconstituição da paisagem e sua distribuição mais eqüitativa, de arborização urbana e de reformulação urbanística, evitandose com isso, a reprodução de padrões insustentáveis de uso do solo.

\section{3 - Metodologia}

A pesquisa sobre o clima urbano e suas aplicações no planejamento pode ser definida como semi-quantitativa, desse modo, além da análise do fato urbano como suporte teórico, é necessário a mensuração das variáveis climáticas. 
O trabalho adota como princípio metodológico o Sistema Clima Urbano elaborado por Monteiro (1976) exposto anteriormente. A investigação climática será realizada no que tange aos aspectos termodinâmicos, isto é, medições climáticas, identificando os locais de ocorrência de ilhas de calor, ilhas de frescor e desconforto térmico.

Para a realização do trabalho, considera-se fundamental as seguintes etapas:

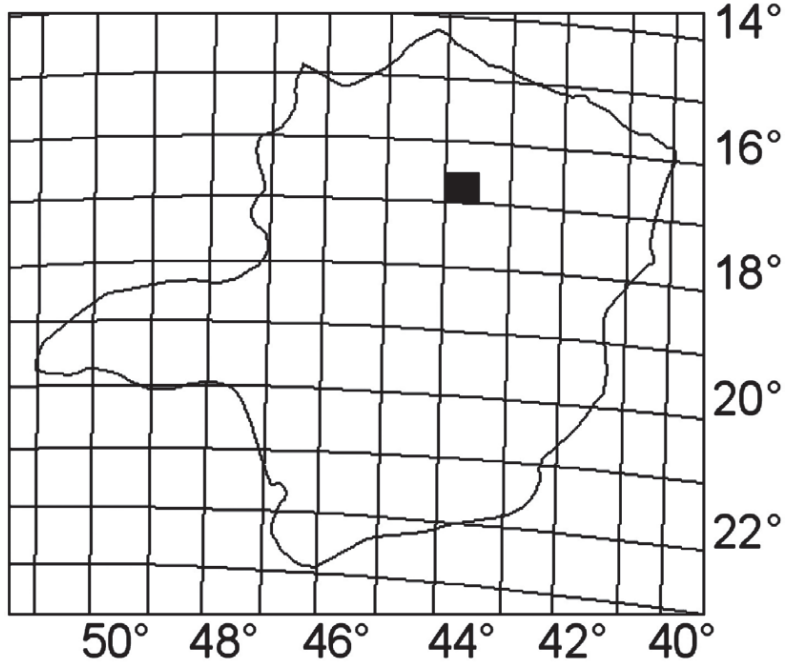

Figura 1: Localização Geográfica de Montes Claros-MG Fonte: Prefeitura Minicipal de Montes Claros
- Revisão bibliográfica sobre os seguintes temas: o processo de urbanização de cidades tropicais como o Brasil, a relação homem-natureza nas cidades; o conforto ambiental e o clima urbano, o planejamento ambiental urbano.

- Coleta de dados, mapas e informações técnicas sobre o município.

- Visita exploratória às áreas mais relevantes do município de modo a compreender a complexidade da estrutura urbana e dos problemas ambientais, sobre o viés climático.

- Análise dos fatores climáticos e ambientais e também dos fatores urbanos e representação sobre um mapa-base, já que clima urbano é definido como um fato natural e um fato urbano. Com isso são necessárias as seguintes atividades:

- levantamento das características relativas ao sítio natural tais como: hipsometria, geomorfologia, direção e velocidade predominante dos ventos. Representação no mapa-base;

- levantamento das variáveis urbanas tais como mapa de uso e ocupação do solo, estruturação e funcionalidade urbana. Representação no mapa-base.

- Divisão da cidade em zonas homogêneas, sob o mapa-base, para a pesquisa de campo, caracterizando usos diferenciados do solo, entre eles:

1 - Área de ocupação horizontal vertical densa.

2 - Área de ocupação horizontal vertical rala.

3 - Área de ocupação horizontal densa.

4 - Área de ocupação horizontal rala.

5 - Loteamentos.

6 - Indústrias.

7 - Predominância significativa de vegetação.

8 - Presença de corpos d'água.

- Definição dos pontos de medição distribuídos em alguns transectos, abrangendo áreas com realidades distintas do município, entre eles:

1 - Região central de maior adensamento e menor cobertura vegetal.

2 - Região industrial.

3 - Região com maior cobertura vegetal e menor adensamento.

4 - Região com menor adensamento e presença de massa d'água. 
Os pontos serão escolhidos de modo a representar condições físicas e urbanas distintas.

As medições de campo serão realizadas em julho de 2006 (inverno), setembro de 2006 (primavera) e dezembro/janeiro de 2007 (verão). Serão coletados os dados de temperatura do ar, umidade relativa, temperatura média radiante, velocidade e direção dos ventos.

Para a coleta de dados serão colocados abrigos nos pontos de medição para a fixação dos sensores de temperatura e umidade a uma altura aproximada de 1,5 metros do solo.

Os dados serão tomados às $6,12,18,21$ horas, representando períodos distintos do dia, inclusive para a verificação da formação de ilhas de calor noturnas.

Os dados obtidos serão conjugados, para parâmetros de verificação, como as informações climáticas obtidas pelas estações meteorológicas do município.

- Em cima do mapa-base de usos de solo homogêneos serão plotados os parâmetros climáticos obtidos no trabalho de campo, para que sejam traçadas as isotermas, subsidio à delimitação da ilha de calor.

- Com a analise das configurações do clima, e dos problemas correlacionados a este, espera-se propor alternativas de uso do solo que contemplem a qualidade ambiental urbana.

\section{4 - Resultados esperados}

Como resultado procura-se testar as possíveis diferenças climáticas e os níveis de conforto percebidos nos distintos pontos da cidade, sob diferentes perfis físicos e sócio-espaciais, de modo a caracterizar algumas ações possíveis de serem incorporadas no planejamento urbano e ambiental, tendo em vista a qualidade do espaço. Evitando-se assim a configuração de problemas ambientais críticos advindos do uso inadequado do solo.

Em relação ao planejamento urbano, por exemplo, o estudo poderia indicar, a partir da análise da legislação urbanística do município, as possíveis correlações entre o atual uso e ocupação do solo com os perfis do clima, podendo alertar para desconformidades passíveis de serem regulamentadas, no âmbito inclusive, da recente revisão do Plano Diretor.

Por se tratar de um município onde a urbanização ainda está acontecendo, e levando em consideração a tendência de crescimento, as investigações climáticas poderiam ser aproveitadas no âmbito da legislação urbanística, através, por exemplo, da atuação antecipada em relação às áreas de expansão urbana, com tendência à verticalização, ou em locais com limitações quanto ao sítio natural, buscando evitar que a urbanização ocorra de maneira inadequada.

O estudo poderia indicar ainda possibilidades bioclimáticas para distintos pontos e zoneamentos, como exemplo o distrito industrial, tendo em vista sua recente expansão com a incorporação de indústrias de grande porte.

Quanto ao planejamento ambiental, os perfis do clima poderiam auxiliar nos planos de reconstituição da paisagem, de arborização, em relação às massas de água e as possibilidades para valorização bioclimática dos recursos hídricos.

Alguns estudos como o de Gómez (2001) para Valência na Espanha, fornece algumas sugestões para o planejamento de áreas verdes ao indicar a quantidade de vegetação necessária para melhorar os índices de conforto, tendo em vista a condição climática mensurada ${ }^{11}$.

O estudo poderia contribuir ainda para indicação dos locais onde a reconstituição da paisagem natural torna-se mais urgente, em relação aos níveis climáticos, contribuindo para uma distribuição mais equânime da cobertura vegetal, já que esta encontra-se na imensa maioria localizada na região sudoeste. 
Essa medida poderia contribuir para uma relação mais justa entre área construída e área natural, pois sabe-se que a expansão de áreas impermeabilizadas horizontal e verticalmente e a conseqüente redução de áreas verdes, alteram significativamente o balanço de energia e o ciclo hidrológico local.

As sugestões a serem levantadas por esse trabalho, a partir dos estudos de climatologia urbana, apontam para a necessária e urgente integração do homem com a natureza para que se possa almejar uma maior qualidade de vida urbana.

Observação: Esse trabalho é parte da dissertação de mestrado, em desenvolvimento, de Patrícia Silva Gomes, como estudante do PósARQ-UFSC.

\section{Notas}

(1) LEFEBRE, H. Direito à cidade. São Paulo: Documentos, 1969.

(2) MONTEIRO, Carlos Augusto de Figueiredo; MENDONÇA, Francisco. Clima urbano. São Paulo: Contexto, 2003.

(3) LOWRY, W. The climate of cities. Scientific American, v. 217, n. 2, p. 15-24, 1967.

(4) OKE, T. R. Canyon geometry and the nocturnal heat island: comparisons of scale model and field observations. Journal of Climatology, v. 1, p. 237-254, 1981.

(5) CHANGNON, S. A; OKE, T. R. apud ASSIS, E. S. A abordagem do clima urbano e aplicações no planejamento da cidade: Reflexões sobre uma trajetória. In: VIII ENCONTRO NACIOAL E IV ENCONTRO LATINO-AMERICANO SOBRE CONFORTO NO AMBIENTE CONSTRUÍDO, 2005, Maceió. Anais... Maceió, 2005.

(6) MARICATO, Ermínia. Brasil, cidades: Alternativas para a crise urbana. Petrópolis: Vozes, 2001.

(7) MONTEIRO, Carlos Augusto de Figueredo. Teoria e clima urbano. São Paulo, n. 25, 1976 (Série Teses e Monografias).

(8) MENDONÇA, Francisco. Clima e planejamento urbano em Londrina. In: MONTEIRO, Carlos Augusto de Figueredo; MENDONÇA, Francisco, op. cit., p. 94.

(9) DUARTE, D. Estado da arte em clima urbano e planejamento. In: NUTAU, 2002, São Paulo. In: Anais... São Paulo: NUTAU/USP, 2002.

(10) Estimativa do IBGE em 2004. BRASIL. Instituto Brasileiro de Geografia e Estatística. Disponível em: <http://www. ibge.gov.br/cidadesat >. Acesso em: 8 mar. 2006.

(11) GÓMEZ, F; TAMARIT, N.; JABALOYES, J. Green zones, bioclimatic studies and human confort in the future development of urban planning. Lanscape and Urban Planning, n. 55, 2001.

\section{Bibliografia}

ACIOlY, Cláudio; FORBES, Davidson. Densidade urbana, dicas e informações para o arquiteto urbanista. Rio de Janeiro: Maduad, 1998.

ASSIS, E. S. Bases teóricas para a aplicação da climatologia ao planejamento urbano. In: IV ENCONTRO NACIONAL SOBRE CONFORTO NO AMBIENTE CONSTRUÍDO, 1997, Salvador. Anais... Salvador: FAUFBA/LACAMANTAC, 1997.

A abordagem do clima urbano e aplicações no planejamento da cidade: Reflexões sobre uma trajetória. In: VIII ENCONTRO NACIONAL E IV ENCONTRO LATINO-AMERICANO SOBRE CONFORTO NO AMBIENTE CONSTRUIIDO, 2005, Maceió-Al. Anais... Maceió-Al: Editora ANTAC, 2005.

BRASIL. Prefeitura Municipal de Montes Claros. <http://montesclaros.mg.gov.br>. Acesso em: 8 mar. 2006.

CULLEN, Gordon. Paisagem urbana. São Paulo: Martins Fontes, 1971.

DUARTE, D. Estado da arte em clima urbano e planejamento. In: NUTAU, 2002, São Paulo. Anais... São Paulo: NUTAU/USP, São Paulo, 2002

GÓMEZ, F; TAMARIT, N.; JABALOYES, J. Green zones, bioclimatic studies and human confort in the future development of urban planning. Lanscape and Urban Planning, n. 55, 2001.

GUERRA, Antônio José Teixeira; DA CUNHA, Sandra Baptista (Orgs.). Impactos ambientais urbanos no Brasil. Rio de Janeiro: Bertrand Brasil, s/d. 
HOUGH, Michael. Naturaleza e ciudad. Barcelona: Gustavo Gili, 1998.

KATZSCHNER, L. Urban climate studies as tools for urban planning and architecture. In: IV ENCONTRO NACIONAL DE CONFORTO NO AMBIENTE CONSTRUÍDO, 1997, Salvador. Anais... Salvador: FAUFBA/LACAM-ANTAC, 1997.

LOMBARDO, M. A. Ilha de calor nas metrópoles: O exemplo de São Paulo. São Paulo: Hucitec, 1985.

LOWRY, W. The climate of cities. Scientific American, v. 217, n. 2, 1967.

MARICATO, Ermínia. Brasil, cidades: Alternativas para a crise urbana. Petrópolis: Vozes, 2001.

MASCARÓ, L. R. Ambiência urbana. Porto Alegre: Sagra: DC Luzzato, 1996.

MONTEIRO, Carlos Augusto de Figueredo. Teoria e clima urbano. São Paulo, n. 25, 1976. (Série Teses e Monografias).

MONTEIRO, Carlos Augusto de Figueiredo; MENDONÇA, Francisco. Clima urbano. São Paulo: Contexto, 2003.

$\mathrm{OKE}$, T. R. Canyon geometry and the nocturnal heat island: Comparisons of scale model and field observations. Journal of Climatology, v. 1, 1981.

OLIVEIRA, P. M. P. Metodologia do desenho urbano considerando os atributos bioclimatizantes da forma urbana e permitindo o controle do conforto ambiental, do consumo energético e dos impactos ambientais. Brasília: UNB, 1993.

ROMERO, M. A. Princípios bioclimáticos para o desenho urbano. São Paulo: Projeto, 1988.

SPIRN, Anne W. O jardim de granito - A natureza no desenho da cidade. São Paulo: Edusp, 1995. 